Article

\title{
Assessing Climate Change in the Trinational Upper Rhine Region: How Can We Operationalize Vulnerability Using an Indicator-Based, Meso-Scale Approach?
}

\author{
Nicolas Scholze * ${ }^{\mathbb{D}}$, Nils Riach and Rüdiger Glaser \\ Department for Physical Geography, Albert-Ludwigs-Universität Freiburg, 79085 Freiburg, Germany; \\ nils.riach@geographie.uni-freiburg.de (N.R.); ruediger.glaser@geographie.uni-freiburg.de (R.G.) \\ * Correspondence: nicolas.scholze@geographie.uni-freiburg.de; Tel.: +49-761-203-9127
}

Received: 17 June 2020; Accepted: 1 August 2020; Published: 6 August 2020

\begin{abstract}
Climate vulnerability assessments are an important prerequisite for establishing successful climate adaptation strategies. Despite a growing number of assessments on the national or global scale, there is still a need for regionalized studies with a high resolution to identify meso-scale vulnerability patterns. In this paper, we present an indicator-based assessment that was carried out in the Trinational Metropolitan Region Upper Rhine within the Interreg-V project Clim'Ability. The analyzed region is characterized by strong cross-border and transnational linkages, similar ecological features and climatic stressors but differing political, administrative, cultural and legal conditions. In this rather complex setting, we operationalized a state-of-the art vulnerability framework using 18 quantified indicators and aggregating them into a vulnerability index. We show that it is possible to downscale the methods used in recent assessments to a regional context with a challenging data situation and discuss strengths and uncertainties. The results are mapped for stakeholder communication purposes. They provide an evidence-base to the identification of the trinational vulnerability pattern and may enable stakeholders and decision-makers to enhance their own climate adaptation planning.
\end{abstract}

Keywords: regional climate vulnerability; assessment; operationalization; indicators; mapping; climate communication; adaptation strategies

\section{Introduction}

The Trinational Metropolitan Region Upper Rhine (TMO, abbreviation of the official German name "Trinationale Metropolregion Oberrhein") is affected by climatic change significantly and in many ways. In recent years, extreme events such as heatwaves $(2003,2015,2019)$, droughts (2018), heavy rainfall seasons (2016) and winter floods along the region's smaller rivers $(2018,2020)$ have repeatedly caused severe economic damage and threatened the lives of exposed persons. In addition, gradual processes such as the rise in mean summer temperatures and the associated increase in cooling energy demand or the decrease in snow cover duration in regional winter sports areas have negative consequences for the economy and contribute to an overall complex climate vulnerability pattern of the TMO, which is rather high compared to other Central European regions [1]. A special feature of the region is its trinationality: while the climate change pattern in the German, French and Swiss parts of the TMO is very similar, each of the three nations has its own socio-cultural settings as well as specific political framings. Risk culture and adaptation strategies differ in the transnational context [2,3]. In this context, the INTERREG research project Clim'Ability (2016-2019) carried out a cross-border climate vulnerability assessment, which is intended to serve as a basis for improved regional climate adaptation 
planning. The overall goal is to minimize the negative effects of climate change on the economy of the TMO by enhancing the adaptation capacity of the region's small and medium enterprises (SMEs).

Many recent publications point out the need for improved knowledge on the spatial pattern and dynamics of climate change on the regional scale [4-6]. Local actors need reliable, specific and high-resolution information in order to adjust and improve their climate adaptation planning. In that context, regionalized vulnerability assessments and climate impact mapping are often desired for improved adaptation planning [4] (p. 845). This also applies for the TMO: even if several climate vulnerability assessments are available that cover the region or parts of it, none of them has a satisfying spatial resolution for local adaptation planning. For instance, the ESPON Climate Project (2011) carried out a state-of-the-art, indicator-based climate vulnerability assessment for the majority of the European countries, achieving a spatial resolution on the NUTS-3-level [7]. It highlighted regional differences on the European scale but did not provide high-resolution information for local stakeholders and lacked information for Switzerland. The German Ministry of the Environment (Umweltbundesamt = UBA) analyzed the climate vulnerability of Germany as a whole, again on the NUTS 3-level, for their national climate adaptation strategy, but of course, this covered only the German districts of the TMO [8]. Moreover, a detailed adaptation strategy is available for the German federal state of Baden-Württemberg [9], which identifies the need for adaptation according to different areas of action and proposes concrete adaptation measures but does not contain high-resolution spatial information. Numerous further studies have been carried out on the subregional or city level, like for example, a detailed analysis of climate risks and opportunities in the Swiss canton of Basel-Stadt [10] or Strasbourg's "Plan Climat 2030," which formulates both climate mitigation and adaptation measures for the Strasbourg city region ("Eurométropole de Strasbourg") but does not consider the German parts of that city region [11].

However, none of these studies investigated the climate vulnerability of the whole TMO across countries and sectors and with higher spatial resolution. The aim of the Clim'Ability project is therefore to close this gap in order to provide regional stakeholders, especially from the business community, with a solid basis for adjusting their climate adaptation processes. In this paper, we present and discuss the methodology and results of the vulnerability assessment carried out within the Clim'Ability project. We show how the conceptual framework was operationalized using an indicator-based, meso-scale approach that might serve as a blueprint for similar assessment in other regions. We also point out how the mapped results of this assessment can be used for enhancing the adaptation capacity of regional stakeholders, thus fostering a transformation towards a more sustainable society.

\subsection{The Study Area and its Regional Climate Vulnerability}

The TMO is located in the center of Europe and is made up of German, French and Swiss subregions. It covers 21,500 $\mathrm{km}^{2}$ and consists of the two French départements Bas-Rhin and Haut-Rhin; the German regions of Baden and southern Palatinate and the Swiss cantons of Basel-Stadt, Basel-Landschaft, Jura, Solothurn and Aargau. In 2016, the population stood at 6.18 million inhabitants, with a rising trend [12].

The topography of the TMO is very diverse (cf. Figure 1): on the one hand, the region is characterized by the Upper Rhine Rift Valley, an extensive plain stretching from Basel to the northern edge of the region, with an extension of ca. $40 \times 200 \mathrm{~km}$. On the other hand, the region has an important share of several low to medium-high mountain ranges: the Black Forest and the Palatinate Forest in Germany, the Vosges in France and the Swiss Jura. The regional topography is complemented by some lower hilly areas such as the Alsatian Sundgau, the Swiss Alpine foreland and the Kaiserstuhl volcanic region. The height spectrum ranges from $91 \mathrm{~m}$ at the Rhine near Germersheim to $1493 \mathrm{~m}$ on the Feldberg summit in the Black Forest mountain range. Both the demographic and topographic structure have a great influence on the spatial pattern of regional climate vulnerability, which varies considerably in response to local climatic and socio-economic parameters. 


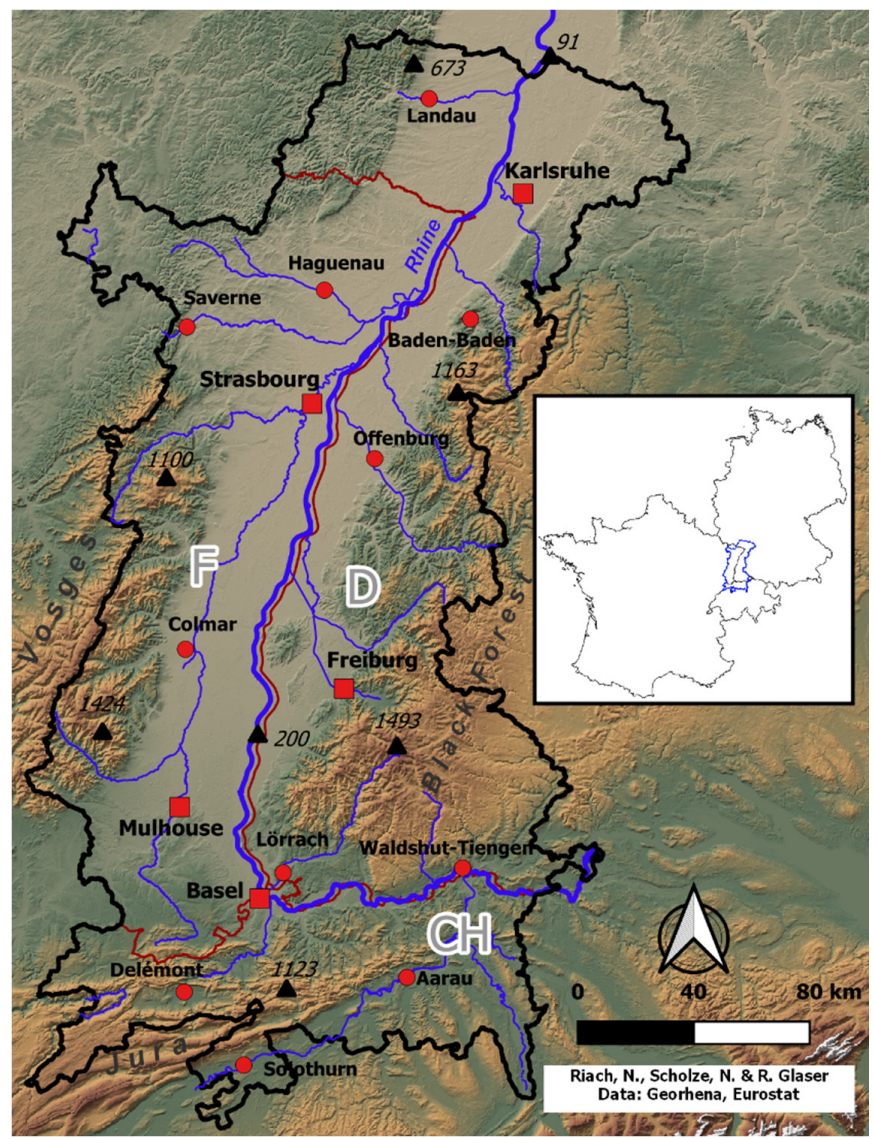

Figure 1. The Trinational Metropolitan Area Upper Rhine (TMO) in its Central European context.

The TMO is a polycentric metropolitan region with a very heterogeneous population density. It contains highly urbanized agglomerations around the core cities of Basel, Strasbourg, Karlsruhe, Freiburg and Mulhouse, which are complemented by a dense network of medium-sized and small towns that tend to form conurbations along the main traffic corridors [13]. It is important to note that all the important urban agglomerations are situated in the lowlands. These densely populated areas are contrasted by peripheral, sparsely populated regions in the mountain ranges. Despite some regional differences and some problematic sectors, the overall economic situation can be described as positive and robust [14]. Generally speaking, the TMO is a dynamic economic area that is home to both internationally active companies and numerous medium-sized enterprises, some of which are referred to as "hidden champions", because they are world market leaders in very specialized industries.

Compared to other Central European regions, the TMO shows a relatively high and multifaceted climate vulnerability $[7,15]$. In the wake of climate change, the main climatic stressors are [16-18]:

(1) a significant increase in heat stress and sultriness, particularly in the lowlands;

(2) an intensification of heavy rain events and winter precipitation with a correspondingly increased flood risk of the Rhine system and its tributaries;

(3) a projected increase of drought frequency and severity, mainly in the summer, which will result in a stronger seasonal accentuation of precipitation;

(4) a decrease of winter snow cover duration that challenges the winter sports-based economies of the higher mountain areas.

Moreover, winter storms have repeatedly caused severe damage in the last decades, but do not show any clear signal of change in current climate projections [19]. 


\subsection{Why that Study Area?}

Due to the topographical and climatic characteristics described above, the region can be regarded as one coherent natural area with very similar effects of climate change. In addition, cross-border interdependencies are very strong, especially in the transnational conurbations such as Basel-Lörrach-Saint-Louis or Strasbourg-Kehl-Offenburg. On the other hand, each of the three nations has developed its own risk culture and to some extent sets different priorities in climate change adaptation $[2,3,20]$. This may alter resilience and, hence, climate vulnerability to the same climatic stressors. It therefore seems appropriate to develop a cross-border adaptation strategy to climate change based on a sound, high-resolution climate vulnerability analysis.

\section{Materials and Methods}

\subsection{Conceptual Framework}

The assessment of vulnerability is seen as a key step towards climate change adaptation and resilience building [21,22]. However, different concepts of vulnerability exist in different scientific communities, some of which vary considerably in their conceptual framework and are subject of controversial discussions [23-26]. Furthermore, as climate vulnerability is a very complex and multi-dimensional phenomenon, there is no generally accepted definition of it, nor a "one-size-fits-all-approach" for its assessment [27]. Factors that determine the most appropriate approach are the goals of the assessment, the scale of the analyzed area, the target group, the data availability and quality in the analyzed area and the time budget and manpower at hand [27] (p. 80). It is therefore necessary to specify, as a first step in this chapter, the conceptual framework as well as the definitions and terminology we worked with in our assessment.

Figure 2 shows the vulnerability concept used within the Clim'Ability project and for the assessment presented in this paper. It was adopted from a concept developed by the UBA [28] as a combination of previous vulnerability concepts, especially those published by Füssel [29] and the IPCC $[4,30]$. The UBA ministry recommends using their concept in future vulnerability assessments [28] (p.18) because it clearly defines the individual terms and-in contrast to some other vulnerability concepts—can be well operationalized. Therefore, we followed this approach to a large extent and adapted it to our needs and the data availability of our study area. It can be stated that similar approaches aiming at a quantified assessment of climate vulnerability in regional contexts use similar conceptual frameworks [7,8,31], although the terminology may slightly differ. A more detailed overview of vulnerability frameworks, their evolution and applicability for assessments is given by Füssel and Klein [23] and Schneiderbauer et al. [27].

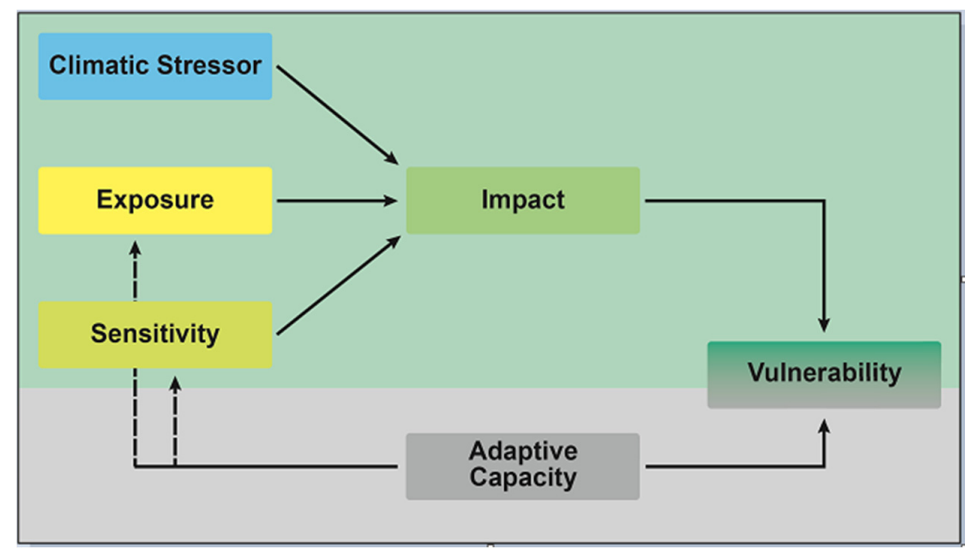

Figure 2. Vulnerability concept of the assessment (modified after UBA 2017). 
Figure 2 highlights the components of our vulnerability concept and their logical relationship. The coloring of the components reflects their level of integration in the present assessment. The colored components against the green background were assessed in a quantitative way, using 18 valid indicators and aggregating them to an index (cf. Figure 3). This index is the main result presented in this paper. The quantitative assessment we carried out can be characterized as a pre-adaptation vulnerability assessment [23] (p. 310). Due to its multi-layered and highly context-dependent characteristics, the adaptive capacity was not quantified on the meso-scale, which is reflected in its grey color. The adaptive capacity is currently being assessed sector-wise using qualitative methods in the second phase of the Clim'Ability project (2019-2022). Since vulnerability results from the joint consideration of impact and adaptive capacity, its coloring shades from green to grey in Figure 2. This illustrates that, in order to obtain a complete view of climate vulnerability in the TMO, the results of the quantitative impact and qualitative adaptative capacity assessment should be regarded synoptically. Nevertheless, we argue that from a sound pre-adaptation assessment it can be deduced where the potential vulnerability in the study area is particularly high and where it is rather low. Hence, our approach aims at identifying meso-scale spatial patterns and cross-sectoral regional hot spots, which is often regarded as a central outcome of vulnerability assessments [26] (p. 272). This serves as a starting point for SMEs to identify their own vulnerabilities and enables them to take measures to increase their adaptive capacities, thus reducing their overall vulnerabilities.

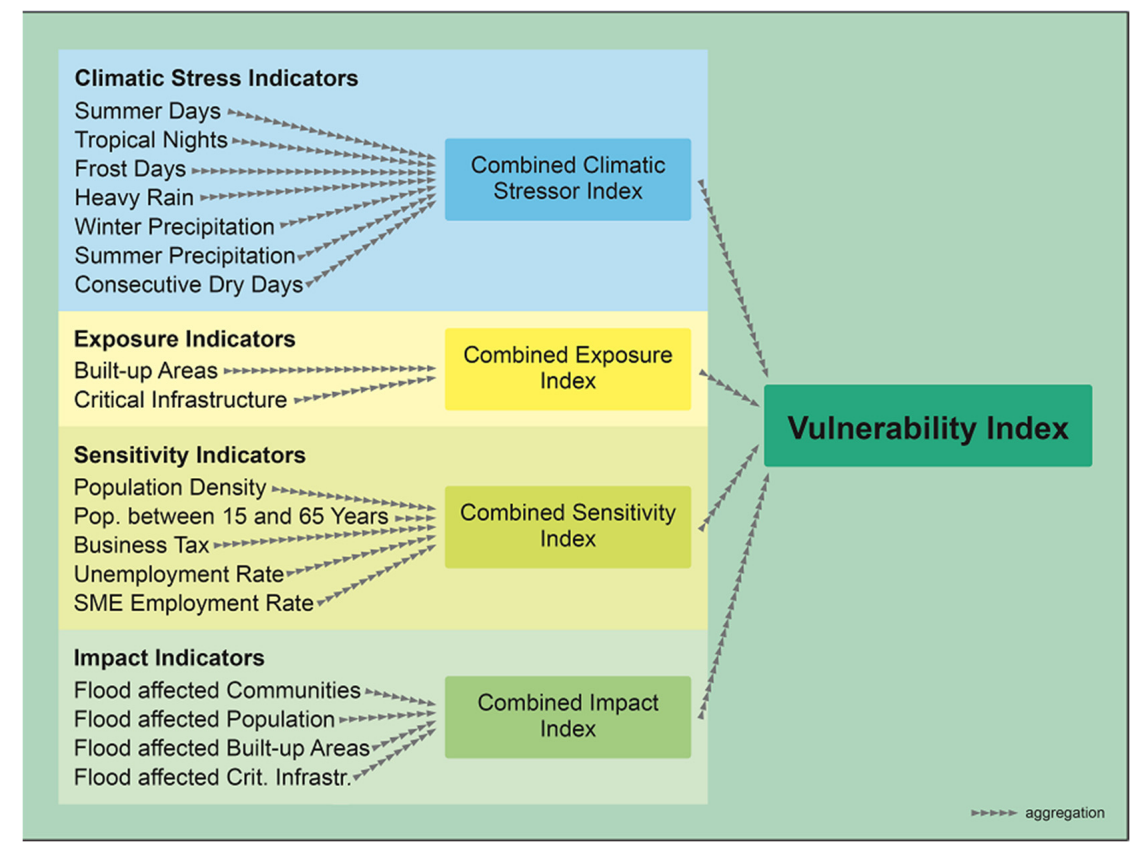

Figure 3. Operationalized vulnerability concept. Indicators, sub-indices and the final Vulnerability Index.

Given the diversity of terms and definitions of the vulnerability components, we consider it necessary to specify the definitions we used in our assessment as follows:

- Climatic stressors are climatic phenomena like heatwaves, droughts, heavy rain events, floods, etc., that cause stress to society and companies. In our study, we integrated only climatic phenomena that show a clear change signal in future climate simulations.

- Exposure means the spatial localization of elements that are exposed to climatic stressors, i.e., the site of a company or an industrial area. This meaning follows the understanding of exposure as presented in the guideline by the UBA [27], and is not in line with other approaches that define climatic hazards or stressors as a part of the exposure, e.g., the IPCC Report 2007 [4]. For 
our approach, we chose this practice-oriented definition that stands in the tradition of a frequently cited vulnerability framework [29] and is used in similar, more quantitatively oriented assessments.

- Sensitivity (in other approaches "susceptibility" or "fragility") describes how an exposed element reacts to a climatic stressor in the function of its socio-economic or demographic characteristics. In our meso-scale assessment, exposed elements are mostly communities and their built-up areas whose sensitivity is determined by several economic and demographic factors.

- Impact refers to an observed or potential negative effect of a climatic stressor on an exposed element in function of its sensitivity. Impacted areas can be identified by overlaying climatic stressors, e.g., flood prone areas and exposed elements (e.g., built-up areas). The impact can be interpreted as the negative or "weak" side of vulnerability.

- Adaptive Capacity is the ability of an element or system to minimize the impact of a climatic stressor by taking adequate measures and/or changing inappropriate behavior. It is closely linked to the concepts of "resilience" and "coping capacity" and represents the "strong" side of vulnerability. The adaptive capacity is determined by a multitude of cultural, technical, institutional, legal, psychological, etc., factors and may have repercussions on exposure and sensitivity, as indicated by the dashed arrows in Figure 2.

- Vulnerability in our study is defined as the aggregation of all potential impacts onto the analyzed system minus its adaptive capacity.

Finally, it should be mentioned that we apply the term meso-scale to a study area of regional size, which is below the national but above the local scale. We thus follow an understanding of the term as formulated, for instance, by Verburg et al. [32], and are aware of differing concepts of the term meso-scale in other human geography publications $[33,34]$.

\subsection{Operationalization of the Vulnerability Framework}

The operationalization of climate vulnerability in quantitative assessments is still a challenge. Due to its complex, multi-faceted nature, climate vulnerability cannot be measured directly. Therefore, it is common to use indicator-based assessments [35]. The chosen indicators should reflect the parameters which make up climate vulnerability. While indicators are usually derived from statistical or climate data, several indicators can be aggregated to an index. The quality of operationalization depends largely on the data used: these should be reliable, freely available and easily accessible. Most of them should be recorded in a continuous way with regular updates, which is why official records and statistics are particularly suitable. Another important issue is data comparability, which is a major challenge in the given trinational context. Overall, the operationalization must be transparent, reproducible and not too time-consuming [36]. In order to facilitate the communication of the results, the index as well as single indicators are often visualized in maps by using GIS [37]. This method of operationalization, which has been followed in many recent studies, is also the core of our assessment.

Our conceptual framework was operationalized in the following steps:

1. A synthesis of relevant climate change impacts in the TMO was worked out, mostly by a literature review of existing assessments and adaptation strategies [1,7-9,17]. In particular, the publication by the Ministry of the Environment of the Federal State of Baden-Württemberg [9] served as a sound qualitative basis for identifying relevant indicators, as it describes many risks and sensitivities of regional enterprises that were derived from recent stakeholder workshops. As a result, we drew an overview scheme that contains and categorizes the most relevant impacts in the given regional context (cf. Appendix A, Figure A1).

2. The relevant impacts for our assessment were selected with a focus on economic vulnerability. The selection process was supported by expert interviews carried out within the Clim'Ability project $[38,39]$. The interviewees were company representatives from various industries in the trinational subareas of the TMO $(n=80)$. Each relevant impact was further refined as an 
indicandum (cf. Tables 1-4), which we define as "a relevant climate change aspect that needs to be operationalized by using an indicator" $[40,41]$.

3. A list of potential indicators was created. Each indicandum had to be covered by at least one indicator. The potential indicators and the vulnerability concept were combined, and the indicators were categorized according to the components of the vulnerability concept (cf. Figure 3).

4. Data were collected for all identified potential indicators. For several indicators, especially in the areas of sensitivity and impact, data from various German, Swiss and French institutions had to be researched and combined. Different national definitions of statistical parameters limited the comparability of the data, and the language barrier was an additional obstacle in some cases.

5. The collected data were validated applying a standardized suitability check for each indicator [42] based on a method published by Birkmann [32]. Indicators with poor data quality or lack of data homogeneity were dropped, e.g., the number of employees and the total number of companies per community. The 18 indicators that met the quality criteria are shown in Figure 3.

6. As a last step, the 18 indicators were statistically analyzed and mapped individually. Then, they were aggregated into sub-indices according to their respective component of the vulnerability concept and finally combined into the Vulnerability Index (Figure 3). The aggregation process is illustrated in Figure 4, where the numbers represent pixel values in the raster files. In order to achieve comparability, the original layers were normalized by calculating their respective Z-scores. They were then reclassified into five classes using the algorithm proposed by Jenks and Caspall [43]. Aggregation was conducted by the addition of class values on a raster pixel basis. These were then again reclassified and aggregated into the layers of the vulnerability components. Aggregating and reclassifying these four layers resulted in the dimensionless Vulnerability Index. The described steps were necessary to enable the vulnerability subcomponents to equally attribute to the Vulnerability Index (cf. Figure 2).

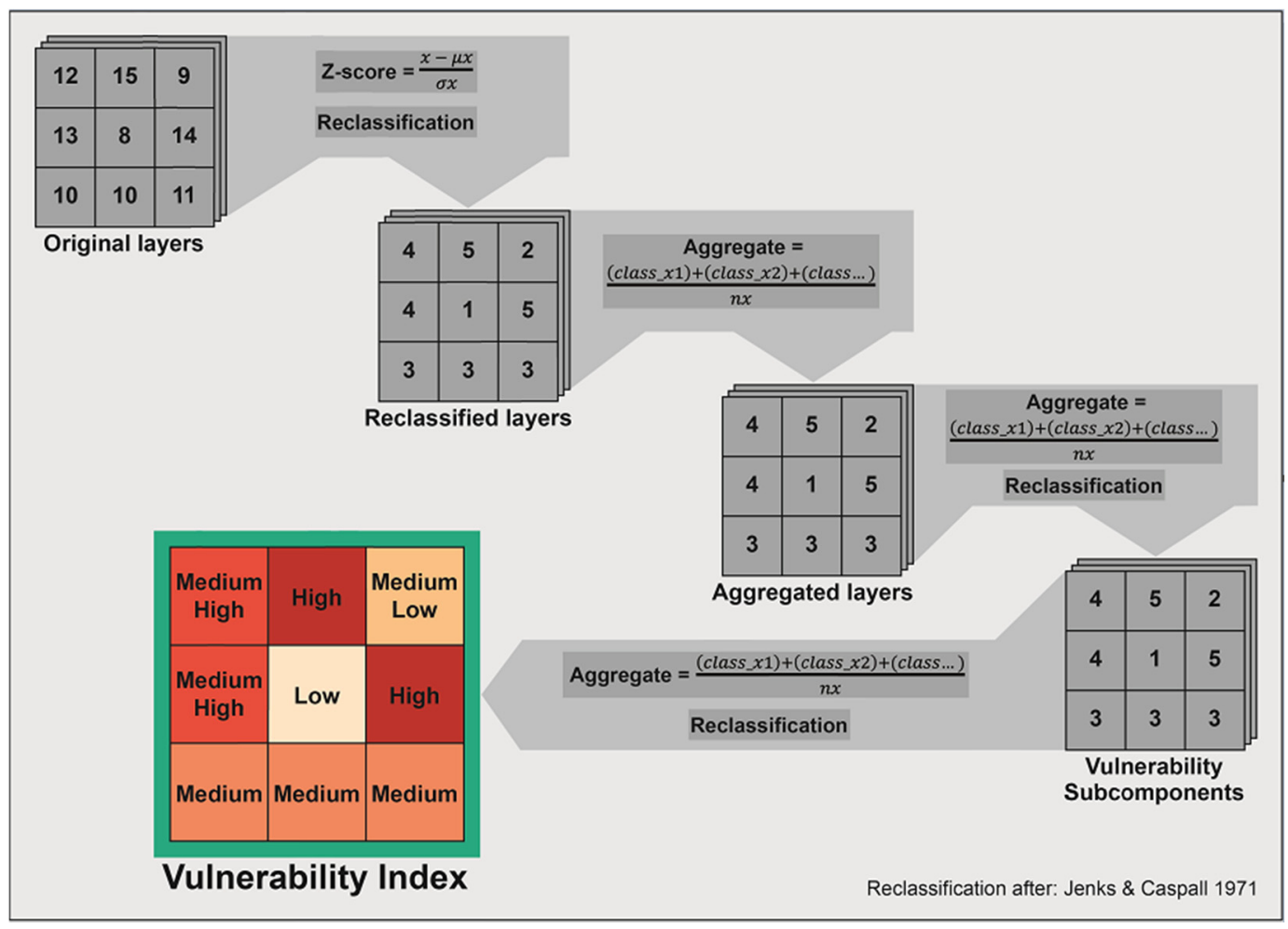

Figure 4. Calculation of the Vulnerability Index. Numbers represent pixel values in raster files. 
Table 1. Climatic stressor indicators used for the operationalization of the climate vulnerability concept.

\begin{tabular}{|c|c|c|c|}
\hline Indicator & Indicandum & Description & Resolution \\
\hline Climatic Stressor & $\begin{array}{l}\text { Change of climatic } \\
\text { stress situations }\end{array}$ & & \\
\hline Tropical Nights ${ }^{1}$ & $\begin{array}{l}\text { Heat stress, lack of } \\
\text { nocturnal cooling }\end{array}$ & $\begin{array}{l}\text { nights/year with a minimum } \\
\text { temperature }>20^{\circ} \mathrm{C}\end{array}$ & ca. $12.5 \times 12.5 \mathrm{~km}$ \\
\hline Summer Days ${ }^{1}$ & $\begin{array}{l}\text { Heat stress, oppressive } \\
\text { humidity, cooling energy } \\
\text { demand }\end{array}$ & $\begin{array}{l}\text { days/year with a maximum } \\
\text { temperature }>25^{\circ} \mathrm{C}\end{array}$ & ca. $12.5 \times 12.5 \mathrm{~km}$ \\
\hline Frost Days ${ }^{1}$ & Decrease of snow cover & $\begin{array}{l}\text { days/year with a minimum } \\
\text { temperature }<0{ }^{\circ} \mathrm{C}\end{array}$ & ca. $12.5 \times 12.5 \mathrm{~km}$ \\
\hline Winter Precipitation ${ }^{1}$ & $\begin{array}{l}\text { Flood risk in winter } \\
\text { months }\end{array}$ & $\begin{array}{c}\text { change of mean precipitation } \\
\text { in December, January and } \\
\text { February in } \%\end{array}$ & ca. $12.5 \times 12.5 \mathrm{~km}$ \\
\hline Summer Precipitation ${ }^{1}$ & $\begin{array}{c}\text { Summer drought risk, } \\
\text { low-water, water } \\
\text { shortages }\end{array}$ & $\begin{array}{l}\text { change of mean precipitation } \\
\text { in June, July and August in } \\
\%\end{array}$ & ca. $12.5 \times 12.5 \mathrm{~km}$ \\
\hline Heavy Precipitation ${ }^{1}$ & $\begin{array}{l}\text { Damages caused by } \\
\text { heavy rain and } \\
\text { subsequent flooding }\end{array}$ & $\begin{array}{l}\text { days/year with a } \\
\text { precipitation }>20 \mathrm{~mm}\end{array}$ & ca. $12.5 \times 12.5 \mathrm{~km}$ \\
\hline $\begin{array}{l}\text { Consecutive Dry Day } \\
\text { Periods }^{1}\end{array}$ & $\begin{array}{l}\text { Drought risk, low-water, } \\
\text { water shortages }\end{array}$ & $\begin{array}{l}\text { days with less than } 1 \mathrm{~mm} \\
\text { precipitation in dry periods } \\
\text { of at least five days }\end{array}$ & ca. $12.5 \times 12.5 \mathrm{~km}$ \\
\hline
\end{tabular}

Table 2. Exposure indicators used for the operationalization of the climate vulnerability concept.

\begin{tabular}{cccc}
\hline Exposure Indicator & Indicandum & Description & Resolution \\
\hline Built-up areas ${ }^{2}$ & $\begin{array}{c}\text { Location of exposed } \\
\text { enterprises and } \\
\text { population }\end{array}$ & built-up area in \% per community & community level \\
Critical & Location of exposed & $\begin{array}{c}\text { incl. roads, cross-border bridges, } \\
\text { railway lines, stations, airports, } \\
\text { hospitals, power lines, power } \\
\text { critical infrastructure }\end{array}$ & $100 \mathrm{~m}$ \\
& & $\begin{array}{c}\text { pylons, power towers, substations, } \\
\text { power plants and generators }\end{array}$ & \\
\hline
\end{tabular}

Data sources: (2) Copernicus Programme (2016); (3) GeoRhena (2018), Open Street Map Contributors (2018). For further details see Appendix A, Table A1.

Table 3. Sensitivity indicators used for the operationalization of the climate vulnerability concept.

\begin{tabular}{|c|c|c|c|}
\hline Sensitivity Indicator & Indicandum & Description & Resolution \\
\hline Population density ${ }^{4}$ & $\begin{array}{l}\text { Density of the potentially } \\
\text { affected population }\end{array}$ & per $\mathrm{km}^{2}$ & community level \\
\hline $\begin{array}{l}\text { Population between } \\
15-65 \text { years }{ }^{4}\end{array}$ & $\begin{array}{c}\text { Share of the population } \\
\text { at working age }\end{array}$ & $\begin{array}{l}\text { percentage of total } \\
\text { population }\end{array}$ & community level \\
\hline Business tax ${ }^{5}$ & $\begin{array}{c}\text { Economic importance of } \\
\text { a community }\end{array}$ & in $€$, without Switzerland & community level \\
\hline SME employment rate ${ }^{6}$ & $\begin{array}{l}\text { SMEs are more sensitive } \\
\text { due to reduced financial } \\
\text { resources }\end{array}$ & $\begin{array}{l}\text { percentage of employees in } \\
\text { enterprises }<200(F) \text { or }<250 \\
\text { employees }(D+C H)\end{array}$ & $\begin{array}{c}\text { community level }(\mathrm{F}, \mathrm{CH}) \\
\text { / NUTS } 3(\mathrm{D})\end{array}$ \\
\hline Unemployment rate ${ }^{7}$ & $\begin{array}{l}\text { Economic situation of a } \\
\text { community }\end{array}$ & percentage per community & $\begin{array}{l}\text { community level }(\mathrm{F}) \\
\text { NUTS } 3(\mathrm{D}+\mathrm{CH})\end{array}$ \\
\hline
\end{tabular}


Table 4. Impact indicators used for the operationalization of the climate vulnerability concept.

\begin{tabular}{|c|c|c|c|}
\hline Impact Indicator & Indicandum & Description & Resolution \\
\hline $\begin{array}{l}\text { Flood affected } \\
\text { communities }\end{array}$ & $\begin{array}{c}\text { flood prone areas in a } \\
100 \text {-year-event }\end{array}$ & $\begin{array}{l}\text { percentage of total } \\
\text { community area }\end{array}$ & $\begin{array}{l}\text { officially defined flood } \\
\text { areas }\end{array}$ \\
\hline $\begin{array}{l}\text { Flood affected } \\
\text { population }\end{array}$ & $\begin{array}{l}\text { Resident population in } \\
\text { flood prone areas } \\
\text { (100-year-event) }\end{array}$ & $\begin{array}{l}\text { percentage of affected } \\
\text { population per } \\
\text { community }\end{array}$ & $1 \mathrm{~km}$ \\
\hline $\begin{array}{l}\text { Flood affected built-up } \\
\quad \text { areas }^{2+8}\end{array}$ & $\begin{array}{l}\text { Built-up areas in flood } \\
\text { prone areas } \\
(100 \text {-year-event })\end{array}$ & $\begin{array}{l}\text { percentage of affected } \\
\text { area per community }\end{array}$ & $100 \mathrm{~m}$ \\
\hline $\begin{array}{l}\text { Flood affected critical } \\
\text { infrastructure } \\
\end{array}$ & $\begin{array}{l}\text { Critical infrastructure in } \\
\text { flood prone areas } \\
\text { (100-year-event) }\end{array}$ & $\begin{array}{l}\text { percentage of affected } \\
\text { critical infrastructure per } \\
\text { community }\end{array}$ & $100 \mathrm{~m}$ \\
\hline
\end{tabular}

\subsection{Data Basis of the used Indicators}

The crux of indicator-based approaches lies at the individual indicator level. The results are only robust if suitable, relevant indicators have been selected and supported by valid data. For this reason, the relevance and some data-specific characteristics of the individual indicators will be briefly discussed below.

The data used for the climatic stressor indicators originate from the EURO-CORDEX initiative, which produces regional climate model (RCM) simulations of the European domain with a resolution of 0.11 degrees (EUR-11, ca. $12.5 \mathrm{~km}$ ) [44]. The extensive data set used in our assessment consisted of projections of many climatic parameters performed by a model ensemble of 16 RCMs. The processing status is November 2016. From the data set, seven parameters were selected which best represent climatic change and its respective stressors in the TMO. The selection was done in close cooperation with representatives of the German Weather Service (DWD) and Meteo France. Those seven parameters were used for creating the climatic indicators shown in Table 1 . Two scenarios (RCP4.5 = "moderate climate change" and RCP8.5 = "business as usual") and three time horizons ("near future" 2021-2050, "medium future" 2041-2070 and "far future" 2071-2100) were included in the evaluation of the climatic stressors. In addition, the range of the projection results was taken into account by including the mean values as well as the 15 th and 85 th percentile of each climate parameter. Thus, 18 maps were created for each climatic stressor [45]. It should be noted that the climatic data refer to change signals and do not contain information on absolute values or reference values.

The two exposure indicators listed in Table 2 represent key elements of economic vulnerability. The indicator "built-up areas" refers to the location of the enterprises, which usually are situated in built-up areas, with a few exceptions (e.g., agriculture and forestry). The indicator covers all types of built-up areas available in the underlying data set CORINE Landcover 2012 [46], i.e., continuous urban fabric, discontinuous urban fabric, industrial or commercial units and port areas. The critical infrastructure (CRITIS) indicator shows the density of CRITIS elements in a very high resolution and was created because all companies are dependent on CRITIS to varying degrees. The disruption of CRITIS impacts public safety and various supply chains and, due to widespread interconnections, can lead to further negative consequences and cascading effects [47]. For example, blow-ups on roads during heatwaves can lead to reduced speed on motor ways, causing delivery delays; flooding and heavy rainfall can lead to disruptions of traffic infrastructure and also increase the probability of landslides and their potential harm on CRITIS; IT-infrastructure can be subject to failure when located in basements and exposed to heavy rain flooding; a decrease of summer precipitation causes reduced river run-off and reduced electricity production in hydrologic power plants along the Rhine River; it furthermore challenges regional water supply, as was the case in 2018. The selection of the 
CRITIS elements was based on the definition of the German Federal Ministry of the Interior on the one hand [48], and on data availability on the other. The data sources of the indicator are Open Street Map and GeoRhena, an organization, which serves as the TMO's geographic information system and provides various harmonized data types covering the whole region [49]. Due to data availability, the indicator focuses on CRITIS in the transport, energy and health sectors.

The five sensitivity indicators listed in Table 3 can be subdivided into two demographic and three economic indicators. The two demographic indicators were selected because enterprises rely on their labor force to function. Consequently, areas with a high "population density" and a low proportion of the "population at working age" (15-65 years) are characterized by an increased sensitivity to climatic stressors, which increases their economic vulnerability. The three economic indicators cover further aspects of economic vulnerability. The indicator "business tax" stands for the economic strength of a municipality and the dependence of the public sector on tax revenues. It is regarded as a key indicator of economic vulnerability [50] and denotes a potential loss: if companies lose profits as a result of climatic events, local business tax revenues will also decline. The indicator "SME employment rate" was chosen because SMEs are generally considered more vulnerable to external risks than larger companies [51,52]. This is partly due to their generally smaller financial resources to mitigate short-term revenue losses and partly to the limited manpower they can invest in strategic risk management. Thus, a municipality with a high SME share among employees is more vulnerable to climatic stressors than a municipality with a low share. Finally, the "unemployment rate" indicator represents the weak side of the current economic situation of the TMO municipalities. Long-term unemployment can lead to inequities within communities. This is a relevant aspect for vulnerability, since adaptive capacity is a result of social status, among others. Moreover, communities affected by high unemployment usually have lower resources for risk governance and institutions, which increases their sensitivity to climatic stressors [7] (p. 126).

Finally, four impact indicators were identified and integrated into the assessment (Table 4). All four indicators relate to the impact of flood events, as floods were the only climatic stressor with a satisfactory data situation. Further potential indicators on the impact of heat waves, heavy rain and droughts did not meet the quality criteria and were dropped. Floods are one of the key risks for Central Europe during climate change [30]. It is likely that they will increase in the TMO both in frequency and magnitude, especially in the winter months. For example, in southern Germany, $69 \%$ of all relevant river gauges in the period of 1932-2015 showed an increasing trend [53], and the probability of centennial events could double in the next three decades [54]. This entails a variety of risks for the regional economy and society. Firstly, the municipalities are affected by floods to varying degrees, which is represented by the indicator "flood affected communities." Secondly, companies can be affected at their location when floods cause damage to buildings or operating equipment, leading to financial losses (indicator "flood affected built-up areas"). Thirdly, the population directly affected by floods is also an indicator of economic vulnerability, as affected persons are unable to go to work during flood events and staff shortages occur (indicator "flood affected population"). Fourthly, when CRITIS is affected, floods can result in power outages, disruption of traffic infrastructure, evacuations, delays in business operations and more cascading effects, which is reflected in the indicator "flood affected critical infrastructure."

\section{Results}

A main result of our assessment is that it is possible to operationalize a practice-oriented, state-of-the-art vulnerability framework on the meso-scale and in a trinational context with a challenging data situation. We derived a climate vulnerability index based on 18 valid indicators that cover all vulnerability components except for adaptive capacity. Thus, the index should be read as a pre-adaptation vulnerability index. The spatial resolution is significantly higher than in previous publications covering the TMO. It results from the superimposing of community areas and the grid cells of the climate projections (ca. $12.5 \times 12.5 \mathrm{~km}$ ). As mentioned above, the outcome of this quantitative 
assessment should be complemented with findings of rather qualitative assessments [38,39] in order to obtain a complete picture of climate vulnerability and the associated risks and impacts on the regional economy.

Figure 5 shows a cartographic representation of the Clim'Ability Index that was designed for the communication of results to regional stakeholders and decision-makers. According to the map, the highest impact occurs in the urban agglomerations around the region's core cities, Strasbourg, Basel, Freiburg, Karlsruhe and Mulhouse. Besides, a couple of medium-sized cities with a high share of flood prone areas like Colmar and Solothurn-Biberist are ranked in the highest impact class. This general pattern confirms the findings of the pan-European ESPON Climate Project, which identified a generally increased vulnerability of urban agglomerations compared to rural areas [55]. This is quite unsurprising, because the highest exposure and sensitivity values are found in the urban agglomerations. A particularity of the TMO are some urban agglomerations, which stretch across two or three countries, namely Strasbourg-Kehl-Offenburg and Basel-Lörrach-Saint-Louis. In these transnational urban corridors, some of the highest impact values occur. At the same time, their adaptive capacity is challenged by the difficulties of cross-border coordination and language barriers. Consequently, another result of our assessment is that in these transnational urban regions, trans-border cooperation with regard to climate adaptation should be fostered by local authorities. Apart from that, the flood prone areas might be overestimated due to the lack of impact indicators covering other climatic stressors like heatwaves or heavy rainfall (cf. Chapter 2).

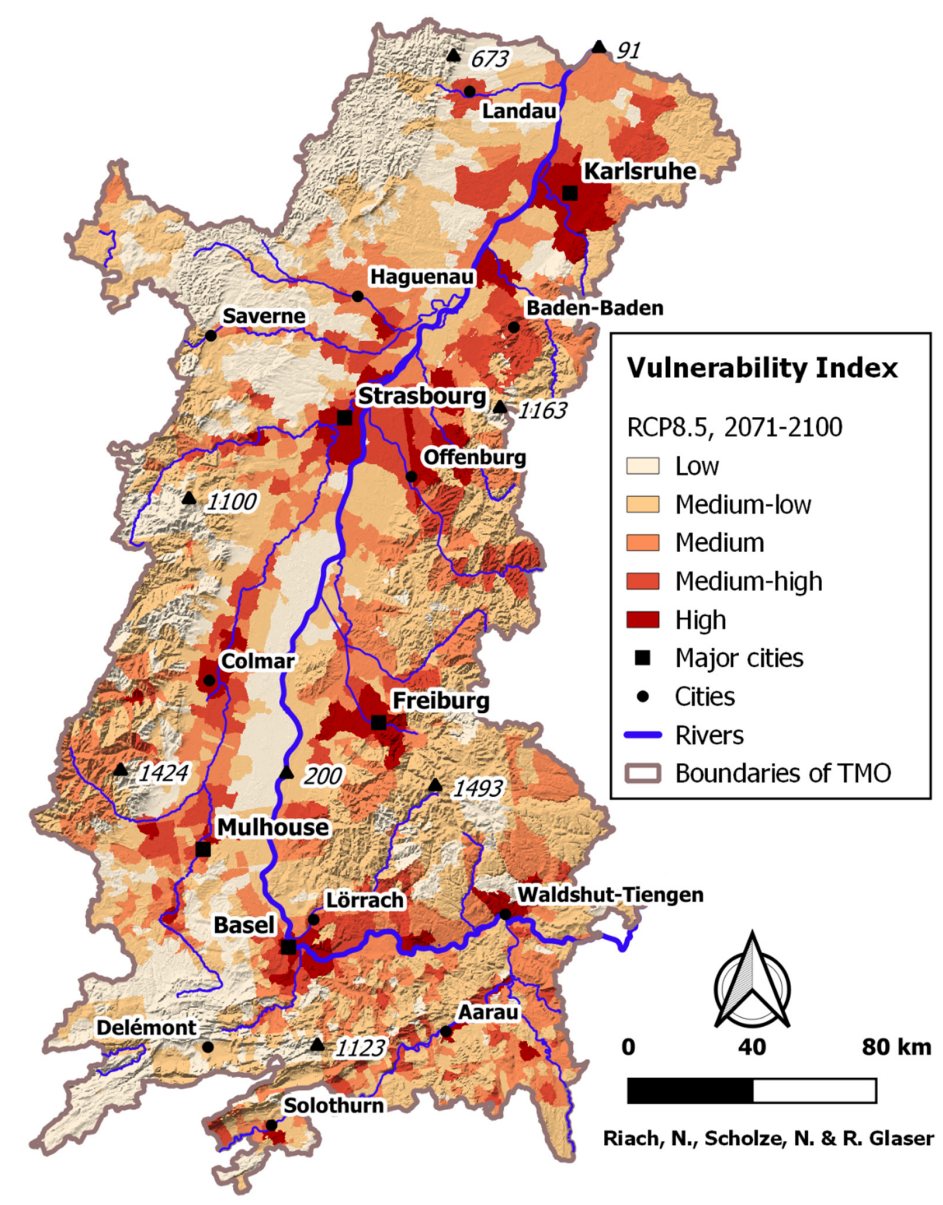

Figure 5. Visualized Vulnerability Index of the TMO under scenario RCP8.5 for the 2071-2100 time frame.

On the other hand, lower impact values often occur in sparsely populated mountainous areas, i.e., in the Vosges Mountains, the Black Forest and the Swiss Jura. Particularly low values are also 
found in the Palatinate Forest and in a narrow strip in the Alsatian Rhine Plain east of Colmar, a largely agricultural, rural area where the considered flood risk is zero. Thanks to technical flood protection measures along the Rhine River (rectification, canalization, dams, flood polders), which were carried out between Basel and Iffezheim in the north of Strasbourg during the 19th and 20th centuries, the flood risk was reduced to events above the 200-year recurrence period. It is noteworthy that the values in the Swiss canton Jura around the city of Delémont might be underestimated due to a lack of flood data. The Palatinate Forest in the northwestern corner of the TMO stands out with particularly low values of climate vulnerability. They can be explained by the low socio-economic density on the one hand, and lower values of climatic stressors on the other: heat stress is lower there than in the adjacent Rhine Plain, and heavy rainfall and flooding are less problematic than in the higher mountain ranges.

In between the extremes, the medium values do not show a general vulnerability pattern because they result from a variety of possible indicator combinations. For instance, medium values can be found in communities with average values of the socio-economic indicators, e.g., in the suburban and peri-urban fringes around Freiburg, Basel-Lörrach or Strasbourg-Haguenau-Baden-Baden. In these areas, the magnitude of climatic stress is similar to the urban agglomerations, whereas socio-economic density is lower, but not as low as in more remote rural areas. Besides, medium values occur in some remote rural areas or mountainous communities that are characterized by a high score of climatic stress, e.g., in the highest parts of the Vosges Mountains and the Southern Black Forest, where the projected change of heavy rain and the reduction of frost days reach maximum values. Both sub-regions are highly dependent on snow-based winter tourism, which determines a relatively high economic vulnerability. Apart from these two examples, many other indicator combinations occur and account for medium vulnerability values in different parts of the region.

The underlying intention of Figure 5 is to create a synthesis map that is catchy, easy to understand and scientifically sound at the same time. To provide good readability and facilitate orientation, we chose quite a large scale and added some geographical features like cities, borders, rivers and a shaded relief. This should help users to roughly locate themselves on the map and identify the index class at their location. The far future time frame (2071-2100) was chosen because the spatial differentiations are more pronounced here. However, the evaluation of the different time frames and scenarios show that the spatial vulnerability pattern is very similar in the near and medium future [45]. The RCP8.5 scenario, too, was used because it highlights the spatial differences more clearly than the RCP4.5 scenario. Unfortunately, the still increasing global greenhouse gas emissions as well as the acceleration of global climate change during these last years show that the more pessimistic RCP6.0 and RCP8.5 scenarios are not implausible [56]. Moreover, even if the RCP8.5 scenario is deemed quite unlikely by some experts [57], it is still a way to explore what could happen if no or very few mitigation measures are realized [58]. In this argumentation, the picture of a negative, highly impacted future might also motivate entrepreneurs to invest in both adaptation and mitigation measures in their company. It is for this purpose that this map was created.

\section{Discussion}

\subsection{Strengths and Shortcomings of the Assessment}

In our assessment, we followed a practice-oriented approach that builds on the vulnerability framework described by Füssel and Klein [29] and takes inspiration from similar quantitative studies like the ESPON Climate Project $[7,55]$ or the vulnerability assessment of Germany carried out by the UBA [8]. More holistic approaches that integrate the assessment of adaptive capacity and socio-cultural dimensions of vulnerability are helpful to deepen the conceptual understanding of climate vulnerability and its transdisciplinary nature. They can be applied in semi-quantitative and sector-specific approaches [59] (pp. 203-206), but proved difficult to be quantified in our trinational, multi-hazard and cross-sector context. We found that the vulnerability framework must not be too complex to be operationalized, and that the number of indicators must remain at a manageable level. 
An important detail of our conceptual framework is the understanding of "exposure," which is in line with the UBA's guideline [28]. It was found to be helpful for the operationalization as it avoids confusion concerning the meaning of "exposure" that occurs when comparing previous frameworks.

Scales are a well-known challenge in vulnerability assessments [60,61], and it is important to critically reflect on the boundaries of the research design and its outcomes [62]. A practical approach therefore needs to mitigate between data resolution and validity. The spatial resolution achieved in our assessment results from the overlapping of community territories and the grid resolution of the climate projections (approx. $12.5 \mathrm{~km}$ ). It is thus significantly higher than in the publications available to date, which reach NUTS-3 level at most, as they were carried out on a national or European scale. Hence, an important goal of the assessment was achieved. Nevertheless, an even higher resolution would be desirable to illustrate intra-municipal differences, especially for large community territories such as Haguenau or Freiburg (both $>150 \mathrm{~km}^{2}$ ). The large forest areas in these municipalities were assessed with the same impact category as the built-up areas, which does not correspond to the climate vulnerability in situ. A possible solution to this problem would be to differentiate between land use types or to assess only built-up areas. However, a clear cartographical representation would then require an even larger scale or format. This example illustrates both the scale dependency of vulnerability assessments [55] and the need to generalize in maps and thus lose accuracy.

Data availability is another crucial aspect in indicator-based vulnerability assessments [59] (p. 203). Therefore, a systematic selection process, as proposed by Birkmann [35], had to be applied in order to ensure the suitability for each indicator. Data availability and quality were good for the climatic data, although reference data for the change signals and projection data on the evolution of hot days $\left(>30^{\circ} \mathrm{C}\right)$ would have been desirable. For the socio-economic indicators, the data availability was also satisfying, since regional authorities provide and update official statistical data. As for the impact indicators, the situation was more problematic: robust data could only be used for floods. Similar data on heavy rain and urban heat islands would have been useful, but the data were not available area-wide or could not be calculated within the given timeframe. Hence, the Vulnerability Index may overestimate flood impacts, while similarly neglecting other impacts (cf. Figure 5).

Given the trinational context, data heterogeneity occurred in several cases in our assessment, mostly due to differing definitions in the three countries. For example, the data on business tax and unemployment rate are not homogenous between France, Germany and Switzerland. We tackled these sources of uncertainties by normalizing the data and by reclassifying them on a country level before aggregating them into a combined data set. A very special case that further illustrates the challenge of data heterogeneity in the trinational context is flood data: due to the EU Flood Directive [63], flood hazard and risk maps have been produced in all EU countries in recent years, although not always with an identical methodology. In Germany, these are managed by the federal states, and in France, by the departments (before the administrative reform of 2016). In Switzerland, flood maps are provided by the cantonal authorities. However, exceptions are the cantons of Solothurn, where the corresponding data had to be obtained from the individual municipalities, and the canton of Jura, for which no flood maps were publicly available. In addition, there are national differences in the recorded return periods: only the 100-year events (centennial floods, “HQ100") were available in all researched data sets and offered sufficient comparability for the derivation of cross-border indicators. When defining minor or extreme flood events, the three countries use different return periods, so the corresponding flood data are not consistent.

A limitation of the data set is that no future data have been integrated for the sensitivity and exposure indicators. The Vulnerability Index therefore reflects temporal dynamics only in terms of climate projections, and not in terms of socio-economic pathways, although the latter are an important emerging aspect in vulnerability assessments $[64,65]$. Recently, efforts have been made to predict socio-economic development using several shared pathways on the global scale [66], but robust regional or local pathways covering the whole 21st century do not yet exist. Consequently, there are no reliable data on the number of jobs per municipality or the predicted business tax revenue in 2050 
or even 2100. Population projections, on the other hand, do exist, but they are associated with great uncertainty, as the development of migration movements cannot be reliably predicted [67]. Moreover, they are usually not available until the end of the 21st century [68]. Ultimately, the risk of including major sources of error in the vulnerability assessment appeared too great, so that only the status quo was assessed for the socio-economic indicators. The Vulnerability Index should therefore be read in such a way that a future climate meets current socio-economic conditions. Nevertheless, the aspect of temporal dynamics is represented by the more robust climate projections. To mitigate this limitation, the socio-economic database can be updated, and the index recalculated as soon as more reliable projections of the socio-economic indicators are available.

\subsection{Starting Points for Possible Adaptation Strategies}

A fundamental goal of vulnerability assessments is to identify the potential harm which may result from the interaction of climate change and the local context [69]. Spatial knowledge of climate change impacts may support the transformation towards a more resilient society. It is therefore crucial to ask whether and how the results of our study can contribute to reduce the negative impacts of climate change in the TMO and its economy. Can there be an added value for society from the dissemination of our results, in the sense of "usable science" [70]?

Given the complexity of climate change impacts and the diversity of economic sectors and enterprises within the region, it is evident that there are no easy solutions that fit for every stakeholder $[38,39]$. The transformation is rather understood as a gradual learning process. Science provides knowledge to regional stakeholders and decision-makers who progressively implement new actions using their new knowledge. In support of this argumentation, the UBA [28] (pp. 8-10) has pointed out that the results of sustainability research should: (1) identify options for action, (2) raise awareness and (3) increase the pressure to act locally. In this last chapter, we discuss if our results address these requirements and can be used as starting points for possible risk reduction strategies or adaptation measures.

First and foremost, the final map (cf. Figure 5) presents highly aggregated information which is good for effective communication with policy-makers, stakeholders and non-scientists [71]. It shows that the magnitude of the potential impacts of climate change is not homogenous throughout the TMO, but that it differs greatly according to the analyzed climatic stressors as well as local socio-economic factors. Such an identification of vulnerability hot spots, by applying a cross-sector perspective, is a desirable outcome of vulnerability assessments [26] (p. 272). The final map may be used for communication purposes, i.e., in stakeholder workshops on regional climate adaptation, as its design should make it easy to understand for non-experts. It suggests that in the higher impacted areas, climate adaptation strategies seem more urgent than in the lower impacted areas. The added value of the map is that it creates spatial knowledge and contributes to raising awareness among local actors such as entrepreneurs or local politicians.

Secondly, our results might be useful for regional planning authorities: since Figure 5 shows some highly impacted transnational urban corridors, this can be seen as an argument to enhance transnational cooperation in terms of climate adaptation. We identify two hypothetical proposals for such transnational cooperation: (1) the trinational agglomeration around Basel could work out a heatwave management plan, setting up a trinational municipal association that comprises the most affected communities, as shown in our map. The plan could compare the heat adjustment measures from Switzerland, France and Germany and combine the most effective measures of the three risk cultures. (2) The Strasbourg-Offenburg corridor could develop a common climate adaptation strategy, possibly by extending the existing "Plan Climat 2030" to the German parts of that city region.

Thirdly, for enterprises that are situated in highly affected areas, the map can serve as a motivation to work proactively on a climate adaptation strategy (ex ante approach) instead of reacting to climate-induced problems, which often results in insufficient adaptation or maladaptation [72]. Nevertheless, there is a possibility of misinterpretation: being located in a low vulnerability area 
does not mean that climate adaptation is not relevant for a given enterprise, as the actual climate vulnerability depends to a big extent on the sector and on individual factors, which were not covered by our assessment. This is an important aspect that needs to be stressed when using the map in stakeholder workshops.

Fourthly, the prepared data and the resulting maps can be used as a basis for web-based climate adaptation tools. This is already being implemented as part of the subsequent Clim'Ability Design (2019-2022) project. The tool "Upper Rhine Climate Inspector" [73], which is already online as a prototype, takes advantage of the high resolution of the data by making them available as an interactive GIS. In this online tool, users can check the projected values of climatic stressors for each community in the TMO and compare them to recent values observed at regional climate stations. The climatic data are provided for three timescales and two scenarios. A synthesis map of the effects of climate change is also available. In a second step, company-specific risks and recommended measures will be added. Besides the didactic aim to present state-of-the-art climate simulation data in a generally understandable way and to make them publicly accessible, the tool fulfills the principle of "timeliness," which is seen as a key feature of usable science [70]. In addition, the differences between the RCP scenarios 4.5 and 8.5 highlight the contrast between moderate and strong climate change, thus serving as a reminder for the expected effects of emissions reductions on overall vulnerability.

\section{Conclusions}

This paper presents an indicator-based approach to assess climate vulnerability in the meso-scale context of the central European TMO region. The framework is characterized by a multi-stressor setting and a trans-national and cross-sectoral perspective that focuses on economic vulnerability. In view of this complex setting and the challenging data situation in the trinational study area, our findings show that it is possible to operationalize a practice-oriented, state-of-the-art vulnerability framework using a quantitative approach and achieve a satisfying spatial resolution. It therefore complements similar indicator-based assessments by downscaling them to the meso-scale, which has so far not been conducted for the TMO and, to our knowledge, for any trans-national context on this scale. The presented methodology may therefore serve as a blueprint for the application to other trans-national contexts. However, we recommend tailor-made designs for the individual situation in other meso-scale regions, taking into account the specific regional climate situation and the socio-economic context.

The assessment builds on a conceptional framework that regards vulnerability as a pre-adaptation product of climatic stressors, exposure, sensitivity and impacts. The operationalization itself comprises of several steps of collecting data and identifying, validating and analyzing individual indicators. The strictly quantitative-empirical data structure allows a standardized calculation process in which the indicators are first aggregated in order to represent the subcomponents of vulnerability. In a second step, they are further aggregated into a dimensionless index, which reflects the complexity of vulnerability as a sum of various climatic stressors and socio-economic parameters. The spatial pattern revealed by the Vulnerability Index was finally visualized in a map. Mapping the index helps communicate the multi-faceted and intangible nature of vulnerability towards climate change. The presented map therefore reduces complexity with the purpose of highlighting meso-scale spatial patterns and cross-sectoral regional hot spots. In order to gain a complete insight of the regional economic vulnerability, the outcome of this quantitative assessment should be complemented with findings of rather qualitative assessments.

Finally, we argue that our assessment and its cartographic visualization presented in this paper offer several starting points for adaptation strategies. The operationalization and the mapping of regional climate vulnerability contribute to raising awareness and enabling knowledge uptake of regional stakeholders. Especially if combined with other outcomes of the Clim'Ability project, like self-diagnosis tools of climate vulnerability and regional climate change projections, this refined knowledge may enable stakeholders to take appropriate measures that can increase their individual 
adaptive capacity. Hence, it might contribute to bridge the science-to-policy-gap, and can be useful to support the transformation towards a more sustainable society in the trinational Upper Rhine Region.

Author Contributions: Conceptualization, N.S. (40\%), R.G. (40\%) and N.R. (20\%); methodology, N.S. (50\%), N.R. (25\%) and R.G. (25\%); formal analysis, N.R. (70\%), N.S. (20\%) and R.G. (10\%); data curation, N.R. ( $80 \%)$ and N.S. $(20 \%)$; writing - original draft preparation, N.S. (70\%), N.R. (20\%) and R.G. (10\%); writing-review and editing, R.G. (50\%) and N.R. (50\%); visualization, N.R. (60\%) and N.S. (40\%); supervision, R.G.; project administration, N.S. $(60 \%)$, R.G. $(30 \%)$ and N.S. $(10 \%)$; funding acquisition, R.G. $(70 \%)$ and N.S. $(30 \%)$. All authors have read and agreed to the published version of the manuscript.

Funding: The research leading to these results has received funding from the European Union in the program 2014-2020 INTERREG V-A France-Germany-Switzerland (Rhin supérieur-Oberrhein) under the project Clim'Ability. The article processing charge was funded by the German Research Foundation (DFG) and the University of Freiburg through the funding program Open Access Publishing.

Acknowledgments: The authors gratefully acknowledge the German Weather Service (DWD, in personam Andreas Walter) for providing high-end climate projection data as well as GeoRhena (in personam Boris Stern) (http://www.georhena.eu/) for providing homogenized socio-economic data of the TMO. The authors also thank their colleague Birgitt Gaida for the graphic design of Figures 2, 3, 4 and A1.

Conflicts of Interest: The authors declare no conflict of interest.

\section{Appendix A}

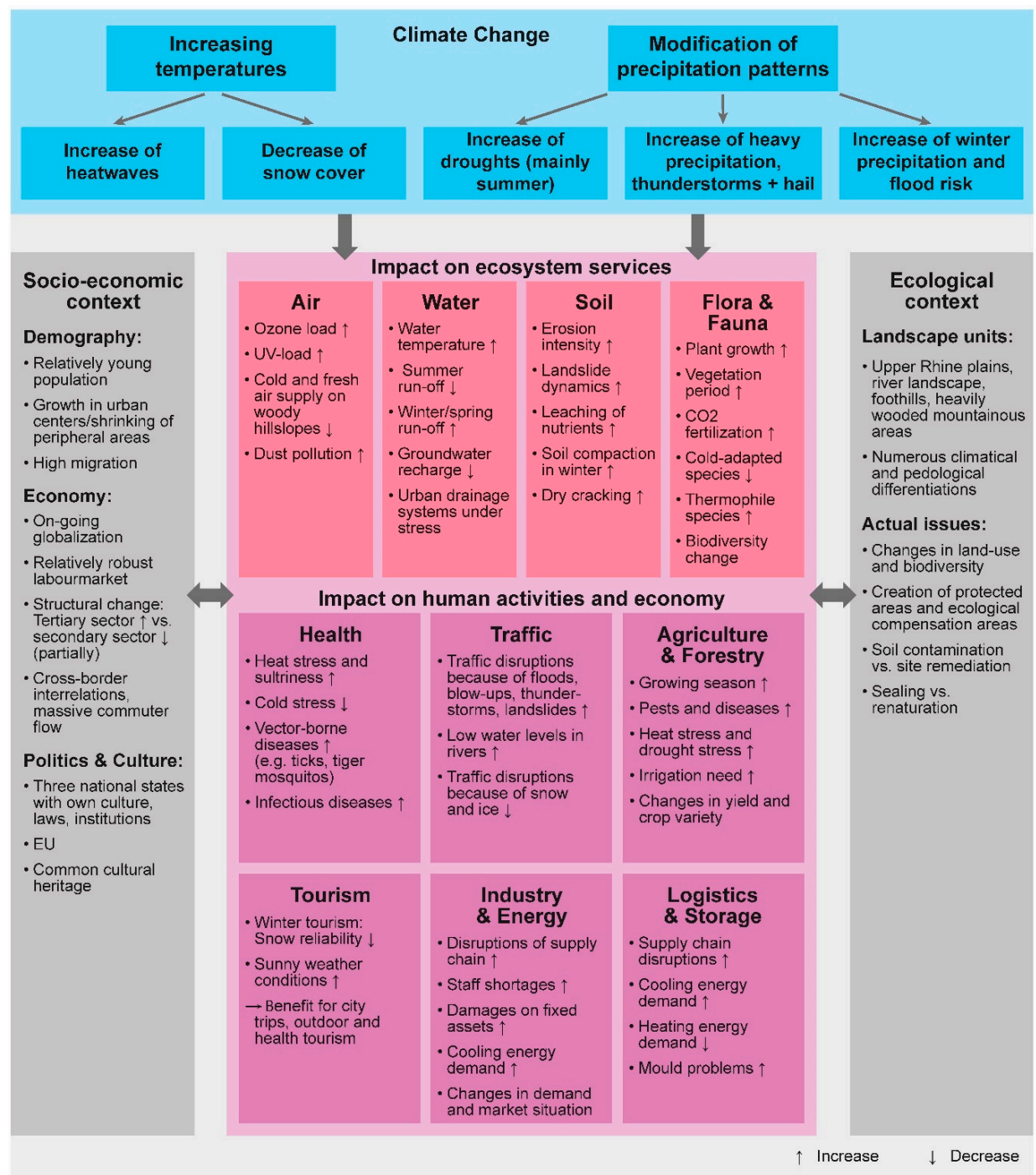

Figure A1. Schematic overview of climate change impacts in the TMO. 
Table A1. Data sources of indicators as listed in Tables 1-4:.

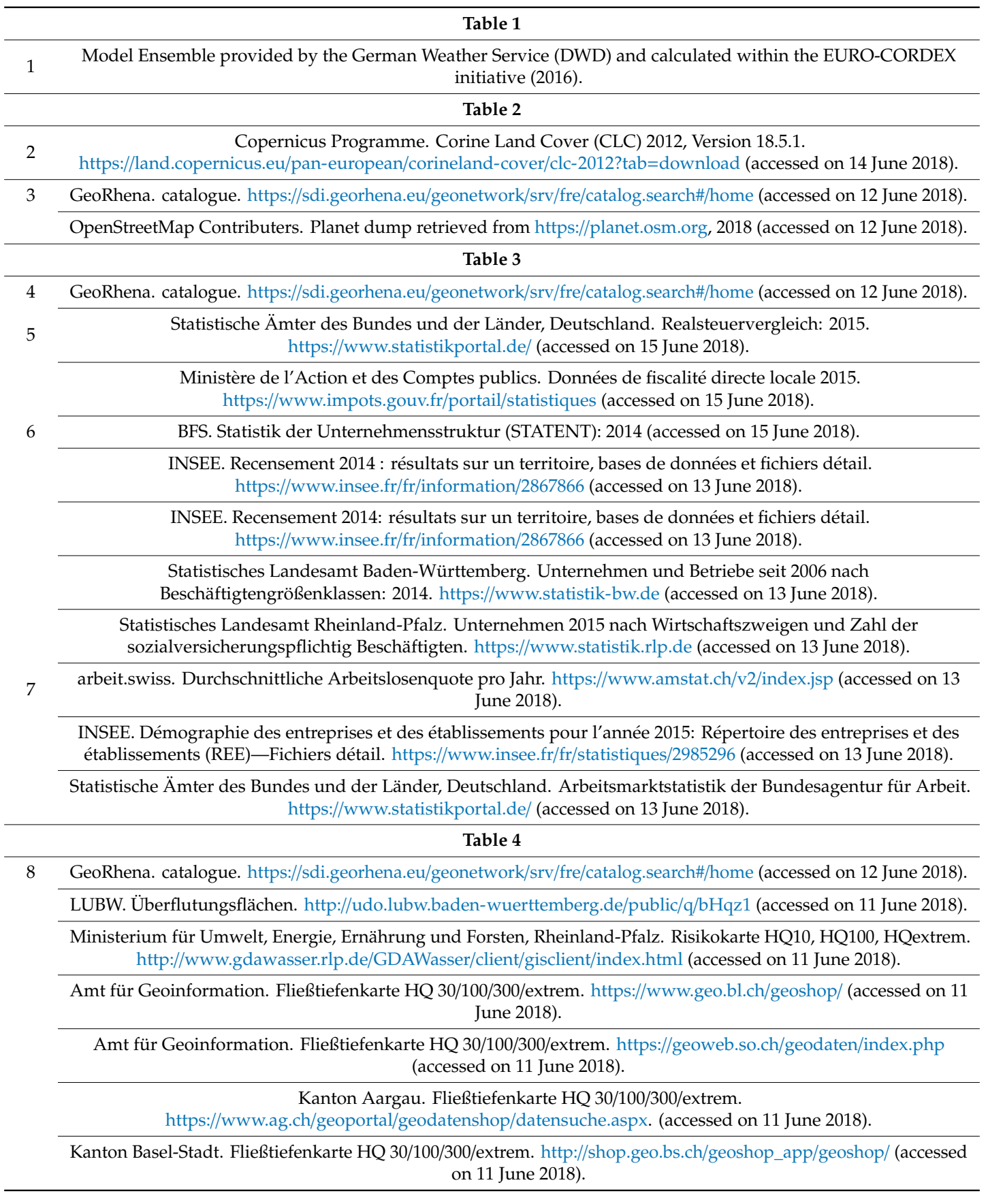

\section{References}

1. European Environment Agency. Climate Change, Impacts and Vulnerability in Europe 2016. An Indicator-Based Report; Publications Office of the European Union: Luxembourg, 2017. [CrossRef]

2. Himmelsbach, I.; Glaser, R.; Schoenbein, J.; Riemann, D.; Martin, B. Reconstruction of flood events based on documentary data and transnational flood risk analysis of the upper Rhine and its French and German tributaries since AD 1480. Hydrol. Earth Syst. Sci. 2015, 19, 4149-4164. [CrossRef]

3. Giacona, F.; Martin, B.; Furst, B.; Glaser, R.; Eckert, N.; Himmelsbach, I.; Edelblutte, C.h. Improving the understanding of flood risk in the Alsatian region by knowledge capitalization: The ORRION participative observatory. Natural Hazards Earth Syst. Sci. 2019, 19, 1653-1683. [CrossRef] 
4. IPCC. Climate Change 2007-Impacts, Adaptation and Vulnerability. Contribution of Working Group II to the Fourth Assessment Report of the Intergovernmental Panel on Climate Change; Parry, M., Canziani, O., Palutikof, J., van der Linden, P., Hanson, C., Eds.; 1. publ; Cambridge University Press: Cambridge, UK, 2007; ISBN 978-0521-70597-4.

5. Regional and Local Adaptation in the EU since the Adoption of the EU Adaptation Strategy in 2013. Available online: https://op.europa.eu/en/publication-detail/-/publication/5a7fd5e0-9c51-11e6-868c-01aa75ed71a1/ language-en (accessed on 17 June 2020).

6. Van den Hurk, B.; Hewitt, C.; Jacob, D.; Bessembinder, J.; Doblas-Reyes, F.; Döscher, R. The match between climate services demands and Earth System Models supplies. Clim. Serv. 2018, 12, 59-63. [CrossRef]

7. ESPON Climate. Climate Change and Territorial Effects on Regions and Local Economies; Final Report Version 31/05/2011, Main Report; ESPON \& IRPUD; TU Dortmund: Dortmund, Germany, 2011.

8. Vulnerabilität Deutschlands gegenüber dem Klimawandel. Available online: https://www.umweltbundesamt. de/sites/default/files/medien/378/publikationen/climate_change_24_2015_vulnerabilitaet_deutschlands_ gegenueber_dem_klimawandel_1.pdf (accessed on 17 June 2020).

9. Strategie zur Anpassung an den Klimawandel in Baden-Württemberg. Vulnerabilitäten und Anpassungsmaßnahmen in relevanten Handlungsfeldern. Available online: https:/um.baden-wuerttemberg. de/fileadmin/redaktion/m-um/intern/Dateien/Dokumente/4_Klima/Klimawandel/Anpassungsstrategie. pdf (accessed on 17 June 2020).

10. Analyse klimabedingter Risiken und Chancen in der Schweiz: Regionale Fallstudie Kanton Basel-Stadt. Available online: https://www.nccs.admin.ch/nccs/de/home/regionen/kantone/basel-stadt.html (accessed on 19 February 2020).

11. Plan Climat 2030, Version Avril 2019. Available online: https://www.strasbourg.eu/plan-climat-2030 (accessed on 19 February 2020).

12. Deutsch-Französisch-Schweizerische Oberrheinkonferenz. Oberrhein/Rhin-Supérieur. Daten und Fakten/ Faits et Chiffres; Statistische Ämter am Oberrhein/Offices statistiques du Rhin Supérieur, Ed.; Deutsch-Französisch-Schweizerische Oberrheinkonferenz: Kehl, Germany, 2018.

13. According to land use data provided by CORINE Landcover. Available online: https://sdi.georhena.eu/ mapfishapp/map/72ba7b3281d9fda4b303ae9ee2f00d2e (accessed on 4 April 2020).

14. Haarich, S.; Hans, S.; Corbineau, C.; Schibler, J.; Brouwer, J.; Deelstra, J. ANALYSE DES PROGRAMMGEBIETS INTERREG V OBERRHEIN. Endbericht. Interreg Programme RHIN SUPERIEUR, Managing Authority REGION GRAND EST STRASBOURG, 11.06.2019. Available online: https://www.interreg-oberrhein.eu/wp-content/ uploads/3-analyse-des-programmgebiets.pdf (accessed on 4 April 2020).

15. Glaser, R. Klimageschichte Mitteleuropas-1200 Jahre Wetter, Klima, Katastrophen, 3rd ed.; WBG: Darmstadt, Germany, 2013.

16. Ouzeau, G.; Déqué, M.; Jouini, M.; Planton, S.; Vautard, R. Le climat de la France au XXIe siècle; Scénarios régionalisés: Édition pour la métropole et les régions d'outre-mer. Available online: https://www.ecologiquesolidaire.gouv.fr/sites/default/files/ONERC_Climat_France_XXI_Volume_4_VF.pdf (accessed on 4 April 2020).

17. Parlow, E.; Scherer, D.; Fehrenbach, U. Regionale Klimaanalyse Südlicher Oberrhein (REKLISO); Regionalverband Südlicher Oberrhein: Freiburg, Germany, 2006.

18. Scherrer, S.C.; Fischer, E.M.; Posselt, R.; Liniger, M.A.; Croci-Maspoli, M.; Knutti, R. Emerging trends in heavy precipitation and hot temperature extremes in Switzerland. J. Geophys. Res. Atmos. 2016, 121, 2626-2637. [CrossRef]

19. Pinto, J.G.; Reyers, M. Winde und Zyklonen. In Klimawandel in Deutschland: Entwicklung, Folgen, Risiken und Perspektiven; Brasseur, G.P., Jacob, D., Schuck-Zöller, S., Eds.; Springer: Cham, Switzerland, 2017; pp. 67-75, ISBN 978-3-662-50396-6.

20. Erfurt, M.; Glaser, R.; Blauhut, V. Changing impacts and societal responses to drought in southwestern Germany since 1800. Reg Environ. Chang. 2019, 19, 2311-2323. [CrossRef]

21. Hyogo Framework for Action 2005-2015: Building the Resilience of Nations and Communities to Disasters. In Proceedings of the World Conference on Disaster Reduction, Kobe, Hyogo, Japan, 18-22 January 2005. Available online: https://www.unisdr.org/2005/wcdr/intergover/official-doc/L-docs/Hyogo-framework-foraction-english.pdf (accessed on 4 June 2020). 
22. IPCC. Managing the Risks of Extreme Events and Disasters to Advance Climate Change Adaptation. Special Report of the Intergovernmental Panel on Climate Change, 1st ed.; SREX; Field, C.B., Barros, V., Stocker, T.F., Qin, D., Dokken, D.J., Ebi, K.L., Mastrandrea, M.D., Mach, K.J., Plattner, G.K., Allen, S.K., Tignor, M., Midgley, P.M., Eds.; Cambridge University Press: New York, NY, USA, 2012; ISBN 978-1-107-02506-6.

23. Füssel, H.-M.; Klein, R.J.T. Climate Change Vulnerability Assessments: An Evolution of Conceptual Thinking. Clim. Chang. 2006, 75, 301-329. [CrossRef]

24. Bohle, H.G.; Glade, T. Vulnerabilitätskonzepte in Sozial- und Naturwissenschaften. In Naturrisiken und Sozialkatastrophen; Felgentreff, C., Glade, T., Eds.; Spektrum Akad. Verl: Berlin, Germany, 2008; ISBN 978-3-8274-1571-4.

25. Weichselgartner, J. Vulnerability as a concept in science and practice. In Atlas Vulnerability and Resilience/Atlas Verwundbarkeit und Resilienz; Pigeon, P., Fekete, A., Hufschmidt, G., Eds.; TH Köln and Universität Bonn: Cologne and Bonn, Germany, 2016; pp. 18-21.

26. Birkmann, J.; Greiving, S.; Serdeczny, O. Das Assessment von Vulnerabilitäten, Risiken und Unsicherheiten. In Klimawandel in Deutschland. Entwicklung, Folgen, Risiken und Perspektiven; Brasseur, G., Jacob, D., Schuck-Zöller, S., Eds.; Springer Spektrum: Hamburg, Germany, 2017; pp. 267-276.

27. Schneiderbauer, S.; Calliari, E.; Eidsvig, U.; Hagenlocher, M. The most recent view of vulnerability. In Science for Disaster Risk Management 2017: Knowing Better and Losing Less; Poljanšek, K., Marin Ferrer, M., de Groeve, T., Clark, I., Eds.; European Commission: Brussels, Belgium, 2017; pp. 68-82, ISBN 978-92-79-60679-3.

28. Buth, M.; Kahlenborn, W.; Greiving, S.; Fleischhauer, M.; Zebisch, M.; Schneiderbauer, S.; Schauser, I. Leitfaden für Klimawirkungs- und Vulnerabilitätsanalysen. Empfehlungen der Interministeriellen Arbeitsgruppe Anpassung an den Klimawandel der Bundesregierung; Umweltbundesamt: Dessau-Roßlau, Germany, 2017. Available online: https://www.umweltbundesamt.de/sites/default/files/medien/377/publikationen/uba_2017_leitfaden_ klimawirkungs_und_vulnerabilitatsanalysen.pdf (accessed on 4 June 2020).

29. Füssel, H.-M. Vulnerability: A generally applicable conceptual framework for climate change research. Glob. Environ. Chang. 2007, 17, 155-167. [CrossRef]

30. IPCC. Climate Change 2014. Impacts, Adaptation, and Vulnerability: Working Group II Contribution to the Fifth Assessment Report of the Intergovernmental Panel on Climate Change; Field, C.B., Barros, V.R., Dokken, D.J., Mach, K.J., Mastrandrea, M.D., Bilir, T.E., Chatterjee, M., Ebi, K.L., Estrada, Y.O., Genova, R.C., Girma, B., Kissel, E.S., Levy, A.N., MacCracken, S., Mastrandrea, P.R., White, L.L., Eds.; Cambridge University Press: Cambridge, UK, 2014; ISBN 978-1-107-64165-5.

31. Schneiderbauer, S.; Zebisch, M.; Kass, S.; Pedoth, L. Assessment of vulnerability to natural hazards and climate change in mountain environments. In Measuring Vulnerability to Natural Hazards: Towards Disaster Resilient Societies, 2nd ed; Birkmann, J., Ed.; United Nations University Press: Tokyo, Japan, 2013; pp. 349-380, ISBN 978-92-808-1202-2.

32. Verburg, P.-H.; de Groot, W.-T.; Veldkamp, A.-J. Methodology for multi-scale land-use change modelling: Concepts and challenges. Global Environmental Change and Land Use; Dolman, A.-J., Verhagen, A., Rovers, C.-A., Eds.; Kluwer: Dordrecht, The Netherlands, 2003; pp. 17-51.

33. Reid, L.; Sutton, P.; Hunter, C. Theorizing the meso level: The household as a crucible of pro-environmental behaviour. Prog. Hum. Geogr. 2010, 34, 309-327. [CrossRef]

34. Hung, L.-S.; Wang, C.; Yarnal, B. Vulnerability of families and households to natural hazards: A case study of storm surge flooding in Sarasota County, Florida. Appl. Geogr. 2016, 76, 184-197. [CrossRef]

35. Birkmann, J. Data, indicators and criteria for measuring vulnerability: Theoretical bases and requirements. In Measuring Vulnerability to Natural Hazards: Towards Disaster Resilient Societies, 2nd ed; Birkmann, J., Ed.; United Nations University Press: Tokyo, Japan, 2013; pp. 80-102, ISBN 978-92-808-1202-2.

36. Fritzsche, K.; Schneiderbauer, S.; Bubeck, P.; Kienberger, S.; Buth, M.; Zebisch, M.; Kahlenborn, W. The Vulnerability Sourcebook: Concept and Guidelines for Standardised Vulnerability Assessments; Deutsche Gesellschaft für Internationale Zusammenarbeit (GIZ) GmbH, Bonn and Eschborn. 2014. Available online: https://www.adaptationcommunity.net/?wpfb_dl=203 (accessed on 4 June 2020).

37. Weis, S.W.M.; Agostini, V.N.; Roth, L.M.; Gilmer, B.; Schill, S.R.; Knowles, J.E.; Blyther, R. Assessing vulnerability: An integrated approach for mapping adaptive capacity, sensitivity, and exposure. Clim. Chang. 2016, 136, 615-629. [CrossRef] 
38. Averbeck, P.; Frör, O.; Gartiser, N.; Lützel, N.; Rudolf, F. Climate change preparedness of enterprises in the Upper Rhine region from a business perspective-A multidisciplinary, transboundary analysis. In NachhaltigkeitsManagementForum|Sustainability Management Forum; Springer: Berlin/Heidelberg, Germany, 2019; Volume 27, pp. 83-93. [CrossRef]

39. Scholze, N.; Glaser, R.; Roy, S. Klimavulnerabilität von Unternehmen in der Metropolregion Oberrhein und ihre Visualisierung anhand von Wirkpfaden. Revue d'Allemagne et des Pays de Langue Allemande 2018, 50, 325-335. [CrossRef]

40. Definition of Indicandum (German): “Ein Indikandum ist der Tatbestand, der in seiner Entwicklung im Zeitablauf mit Indikatoren abgebildet wird [ .. . ." In: Glossar zu Umwelt- und Nachhaltigkeitsindikatoren, Statistisches Bundesamt, Ed., IVB 3. Available online: https://www.bmu.de/fileadmin/bmu-import/files/pdfs/ allgemein/application/pdf/csd_04.pdf (accessed on 20 March 2020).

41. Müller, F.; Wiggering, H. Umweltziele und Indikatoren. Wissenschaftliche Anforderungen an ihre Festlegung und Fallbeispiele; Springer: Berlin/Heidelberg, Germany, 2004.

42. Riach, N. Development of a GIS-based Data Infrastructure for the Assessment of Climate Vulnerability in the Trinational Metropolitan Region Upper Rhine Valley. Master's Thesis, Albert-Ludwigs-University Freiburg, Breisgau, Germany, 2018.

43. Jenks, G.F.; Caspall, F.C. Error on Choroplethic Maps: Definition, Measurement, Reduction. Ann. Assoc. Am. Geogr. 1971, 61, 217-244. [CrossRef]

44. Jacob, D.; Petersen, J.; Eggert, B.; Alias, A.; Christensen, O.B.; Bouwer, L.M.; Braun, A.; Colette, A.; Déqué, M.; Georgievski, G.; et al. EURO-CORDEX: New high-resolution climate change projections for European impact research. Reg. Environ. Chang. 2014, 14, 563-578. [CrossRef]

45. Riach, N.; Scholze, N.; Glaser, R. Mapping Climate Change Impacts: The case study of the Trinational Metropolitan Area Upper Rhine. 2020; (unpublished, manuscript in prep.).

46. Copernicus Programme (Ed.) Corine Land Cover (CLC) 2012, Version 18.5.1. 2016. Available online: https://land.copernicus.eu/pan-european/corine-land-cover/clc-2012 (accessed on 12 January 2020).

47. Pescaroli, G.; Alexander, D. Critical infrastructure, panarchies and the vulnerability paths of cascading disasters. Nat. Hazards 2016, 82, 175-192. [CrossRef]

48. National Strategy for the Protection of Critical Infrastructures (KRITIS-Strategie). Federal Ministry of the Interior, Eds. 17.06.2009. Available online: https:/www.bbk.bund.de/SharedDocs/Downloads/BBK/DE/ Downloads/Kritis/CI_Sectors_Subsectors.pdf?_blob=publicationFile (accessed on 26 March 2020).

49. GeoRhena. Available online: https://www.georhena.eu/de/GeoRhena_DE (accessed on 26 March 2020).

50. Cardona, O.D.; van Aalst, M.; Birkmann, J.; Fordham, M.; McGregor, G.; Perez, R.; Pulwarty, R.; Schipper, E.L.F.; Sinh, B.T. Determinants of Risk: Exposure and Vulnerability. In Managing the Risks of Extreme Events and Disasters to Advance Climate Change Adaptation: Special Report of the Intergovernmental Panel on Climate Change, SREX, 1st ed; IPCC, Ed.; Cambridge University Press: New York, NY, USA, 2012; pp. 65-108, ISBN 978-1-107-02506-6.

51. Crichton, D. Climate Change and Its Effects on Small Businesses in the UK; AXA Insurance UK: London, UK, 2006.

52. Wedawatta, G.; Ingirige, B.; Jones, K. Climate Change and Construction Sector SMEs: Vulnerability, Consequences and Resilience. In Proceedings of the 8th Workshop and Meeting of the CIB W108 Climate Change and the Built Environment, Politecnico di Milano, Milano, Italy, 12-16 March 2009; Gattoni, L.P., Poli, T., Paolini, R., Eds.; Available online: https://www.researchgate.net/publication/303497992 Climate_Change_and_Construction_Sector_SMEs_Vulnerability_Consequences_and_Resilience (accessed on 4 June 2020).

53. KLIWA: Klimawandel in Süddeutschland-Veränderungen von Meteorologischen und Hydrologischen Kenngrößen. Klimamonitoring im Rahmen der Kooperation KLIWA. Monitoringbericht 2016. Available online: https://www.kliwa.de/_download/KLIWA_Monitoringbericht_2016.pdf (accessed on 1 April 2020).

54. Alfieri, L.; Burek, P.; Feyen, L.; Forzieri, G. Global warming increases the frequency of river floods in Europe. Hydrol. Earth Syst. Sci. 2015, 19, 2247-2260. [CrossRef]

55. Greiving, S. Multi-risk and vulnerability assessment of Europe's regions. In Measuring Vulnerability to Natural Hazards: Towards Disaster Resilient Societies, 2nd ed; Birkmann, J., Ed.; United Nations University Press: Tokyo, Japan, 2013; pp. 277-550, ISBN 978-92-808-1202-2. 
56. cf. a tweet of climatologist Glen Peters in which he updates a figure on observed global GHG emissions and assumed emissions in various scenarios. Available online: https://witter.com/Peters_Glen/status/ 1160518968169390080 (accessed on 10 April 2020). Original article: Peters, G.; Andrew, R.; Boden, T. et al. The challenge to keep global warming below $2{ }^{\circ} \mathrm{C}$. Nat. Clim. Chang. 2013, 3, 4-6. [CrossRef]

57. Hausfather, Z.; Peters, G.P. Emissions - the 'business as usual' story is misleading. Comment - Setting the agenda in research. Nature 2020, 577, 618-620. [CrossRef]

58. Remark of Climatologist and Sustainability Researcher Detlef van Vuuren on the Website Carbonbrief.org. Available online: https:/www.carbonbrief.org/explainer-the-high-emissions-rcp8-5-global-warmingscenario (accessed on 10 April 2020).

59. Birkmann, J.; Cardona, O.D.; Carreño, M.L.; Barbat, A.H.; Pelling, M.; Schneiderbauer, S.; Kienberger, S.; Keiler, M.; Alexander, D.; Zeil, P.; et al. Framing vulnerability, risk and societal responses: The MOVE framework. Nat Hazards 2013, 67, 193-211. [CrossRef]

60. Fekete, A.; Damm, M.; Birkmann, J. Scales as a challenge for vulnerability assessment. Nat. Hazards 2010, 55, 729-747. [CrossRef]

61. Adger, W.N.; Arnell, N.W.; Tompkins, E.L. Adapting to climate change: Perspectives across scales. Glob. Environ. Chang. 2005, 15, 75-76. [CrossRef]

62. Preston, B.L.; Yuen, E.J.; Westaway, R.M. Putting vulnerability to climate change on the map: A review of approaches, benefits, and risks. Sustain. Sci. 2011, 6, 177-202. [CrossRef]

63. EU Flood directive, (German version). Available online: https://eur-lex.europa.eu/LexUriServ/LexUriServ. do?uri=OJ\%3AL\%3A2007\%3A288\%3A0027\%3A0034\%3Ade\%3APDF (accessed on 1 April 2020).

64. Kriegler, E.; O’Neill, B.C.; Hallegatte, S.; Kram, T.; Lempert, R.J.; Moss, R.H.; Wilbanks, T. The need for and use of socio-economic scenarios for climate change analysis: A new approach based on shared socio-economic pathways. Glob. Environ. Chang. 2012, 22, 807-822. [CrossRef]

65. Birkmann, J.; Mechler, R. Advancing climate adaptation and risk management. New insights, concepts and approaches: What have we learned from the SREX and the AR5 processes? Clim. Chang. 2015, 133, 1-6. [CrossRef]

66. van Vuuren, D.P.; Riahi, K.; Calvin, K.; Dellink, R.; Emmerling, J.; Fujimori, S.; KC, S.; Kriegler, E.; O’Neill, B. The Shared Socio-economic Pathways: Trajectories for human development and global environmental change. Glob. Environ. Chang. 2017, 42, 148-152. [CrossRef]

67. Bijak, J.; Migration Forecasting: Beyond the limits of uncertainty. Global Migration Data Analysis Centre, Data Briefing Series, 2016, 6. Available online: https://publications.iom.int/system/files/gmdac_data_briefing series_issue_6.pdf (accessed on 1 June 2020).

68. For Instance, the German Federal State of Baden-Württemberg Provides Population Forecasts on the District Level only until 2035. Projections. Available online: https://www.statistik-bw.de/BevoelkGebiet/ Vorausrechnung/Kreisdaten.jsp (accessed on 28 May 2020).

69. Cutter, S.; Osman-Elasha, B.; Campbell, J.; Cheong, S.-M.; McCormick, S.; Pulwarty, R.; Supratid, S.; Ziervogel, G. Managing the Risks from Climate Extremes at the Local Level. In Managing the Risks of Extreme Events and Disasters to Advance Climate Change Adaptation: Special Report of the Intergovernmental Panel on Climate Change SREX, 1st ed; IPCC, Ed.; Cambridge University Press: New York, NY, USA, 2012; pp. 291-338, ISBN 978-1-107-02506-6.

70. Ford, J.D.; Knight, M.; Pearce, T. Assessing the 'usability' of climate change research for decision-making: A case study of the Canadian International Polar Year. Glob. Environ. Chang. 2013, 23, 1317-1326. [CrossRef]

71. Fancy, S.G.; Gross, J.E.; Carter, S.L. Monitoring the condition of natural resources in US national parks. Environ. Monit. Assess. 2009, 151, 161-174. [CrossRef]

72. Magnan, A.K.; Schipper, E.L.F.; Burkett, M.; Bharwani, S.; BURTON, I.; Eriksen, S.; Gemenne, F.; Schaar, J.; Ziervogel, G. Addressing the risk of maladaptation to climate change. WIREs Clim. Chang. 2016, 7, 646-665. [CrossRef]

73. The Upper Rhine Climate Inspector. Available online: https://gis.clim-ability.eu/ (accessed on 4 June 2020).

(C) 2020 by the authors. Licensee MDPI, Basel, Switzerland. This article is an open access article distributed under the terms and conditions of the Creative Commons Attribution (CC BY) license (http://creativecommons.org/licenses/by/4.0/). 